\title{
CURRÍCULO, CULTURA E \\ CIDADANIA: A PRODUÇÃO DE SABERES PARA O EXERCÍCIO \\ DEMOCRÁTICO NA EDUCAÇÃO BÁSICA
}

\author{
Mônica da Silva Gallon * \\ José Luís Schifino Ferraro ** \\ Marícia da Silva Ferri *** \\ Melissa Guerra Simões Pires ****
}

\section{RESUMO}

O estudo objetiva investigar as percepções de professores de educação básica - atuantes anos finais do ensino fundamental e ensino médio - sobre o currículo e suas possibilidades para proposição de práticas cidadãs na escola. Para isso, aplicou-se um questionário buscando identificar nos sujeitos suas concepções quanto a cidadania, de que forma acreditam contribuir com suas disciplinas para a construção de saberes e fomento à cultura de modo a permitir aos estudantes a construção de práticas cidadãs e como a disciplina ministrada por esse docente poderia contribuir para uma participação mais ativa dos estudantes em uma sociedade democrática. As respostas dos 29 docentes participantes foram submetidas à Análise de Conteúdo, resultando em seis categorias: (I) relação indivíduo/conhecimento; (II) relação sujeito/poder-saber; (III) relação cidadão/ambiente; (IV) relação currículo/cidadania; (V) interdisciplinaridade; (VI) relação 
professor/escola. Entre as fragilidades apontadas, emerge a necessidade de uma proposta curricular efetiva, que abarque aproximações entre os atores (entre docentes; entre setores; entre escola e comunidade), trazendo clareza às questões, estabelecendo possíveis parcerias, atuando democraticamente nas decisões da escola e com isso, efetivando a construção cidadã na prática.

Palavras-chave: Cidadania. Currículo. Educação básica.

\section{ABSTRACT}

The aim of this study is to investigate the perceptions of teachers of basic education - in the final years of elementary and secondary education - about the curriculum and its possibilities for proposing citizen practices in school. For this, a questionnaire was applied seeking to identify in the subjects their conceptions about citizenship, in what way they believe to contribute with their disciplines for the construction of knowledge and promotion of culture in order to allow students to construct citizen practices and how the discipline taught by this teacher could contribute to a more active participation of students in a democratic society. The responses of the 29 participating teachers were submitted to Content Analysis, resulting in six categories: (I) individual / knowledge relation; (II) subject / power-knowledge relationship; (III) citizen / environment relationship; (IV) curriculum / citizenship relationship; (V) interdisciplinarity; (VI) teacher / school relationship. Among the weaknesses pointed out, there is a need for an effective curricular proposal, which includes approximations among the actors (between teachers, between sectors, between school and community), bringing clarity to issues, establishing possible partnerships, acting democratically in school decisions and with this, making the construction of citizenship practical.

Keywords: Citizenship. Curriculum. Basic education.

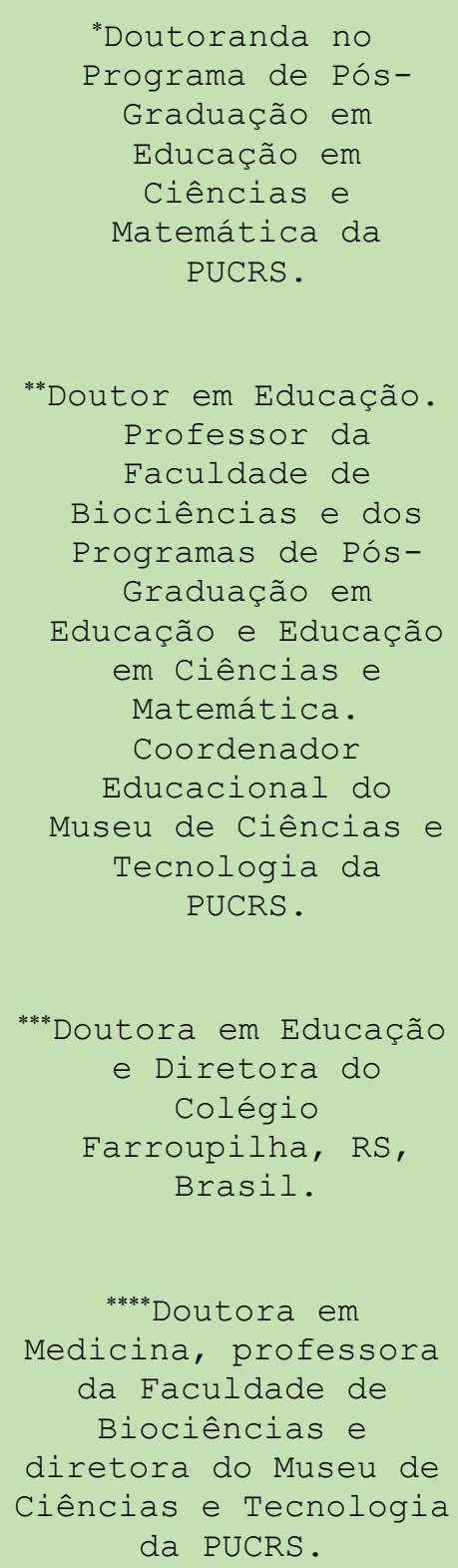
da PUCRS. 


\section{CURRÍCULO, CULTURA E CIDADANIA: INTRODUÇÃO}

A escola é um espaço reconhecidamente social, exercendo funções que vão muito além do ensino e aprendizagem conhecimentos escolares desenvolvidos pelas disciplinas ao longo da educação básica. Constitui-se um ambiente povoado por diferentes culturas, hábitos, crenças, impregnado por ideologias, questões sociológicas e políticas, tornando o currículo um artefato social e cultural. (MOREIRA, TADEU, 2011).

Moreira e Candau (2007, p. 18) concebem currículo como "as experiências escolares que se desdobram em torno do conhecimento, em meio as relações sociais, e que contribuem para a construção das identidades de nossos/as estudantes" e concluem como sendo um "conjunto de esforços pedagógicos desenvolvidos com intenções educativas". As Diretrizes Curriculares Nacionais da Educação Básica (BRASIL, 2013, p. 25) esclarecem que:

Toda política curricular é uma política cultural, pois o currículo é fruto de uma seleção e produção de saberes: campo conflituoso de produção de cultura, de embate entre pessoas concretas, concepções de conhecimento e aprendizagem, formas de imaginar e perceber o mundo.

Sendo assim, o currículo é um documento intencional, livre de neutralidade e intimamente relacionado a transmissão do conhecimento social (MOREIRA; TADEU, 2011). As políticas curriculares devem abranger as propostas e práticas, planejamentos discutidos no coletivo escolar, norteados pela realidade de cada comunidade, com olhos para dentro e fora dos muros da escola. Em suma, trata-se de um artefato permeado por relações de poder, interessado em compor uma identidade e organizado a partir dequestões que irão compor e guiar o processo de ensino e aprendizagem de determinado grupo. Todo elemento que passe por uma escolarização pode vir a integrar o currículo.

Nesse sentido, a formação cidadã enquanto prática educativa, deve estar presente atravessando as disciplinas, em todos os anos escolares. Os Parâmetros Curriculares Nacionais (BRASIL, 1998, p. 7) apontam como um objetivo a ser desenvolvido pela educação:

A compreensão da cidadania como participação social e política, assim como exercício de direitos e deveres políticos, civis e sociais, adotando no dia-a-dia, atitudes de solidariedade, cooperação e repúdio às injustiças, respeitando o outro e exigindo para si o mesmo respeito.

@rquivo Brasileiro de Educação, Belo Horizonte, v. 5, n. 12, set-dez, 2017. 
Numa visão mais conservadora, a cidadania é percebida como via de acesso dos indivíduos a serviços e bens, porém, a partir de uma educação que preconize a formação cidadã, prevê-se a participação ativa desses sujeitos nas decisões públicas, assumindo direitos e também deveres, de forma organizada em "condições de vida minimamente civilizadas" (BRASIL, 2013, p.21).

Sendo a cidadania um ponto a ser trabalhado por todos os docentes durante todo processo de escolarização, independentemente de suas formações e disciplinas de atuação, nosso problema de pesquisa nesse estudo consistiu-se: De que modo a prática cidadã é compreendida e como essa perpassa o trabalho cotidiano de professores da educação básica? Com isso, objetivou-se: Investigar as percepções de professores de educação básica sobre o currículo e suas possibilidades para proposição de práticas cidadãs na escola.

Para esta pesquisa, adotamos o uso de um questionário online, onde professores dos estados de Minas Gerais e Rio Grande do Sul, atuantes na educação básica - em especial docentes dos anos finais do ensino fundamental e ensino médio foram convidados a responder sobre suas práticas pedagógicas as quais atribuíram relação à formação cidadã dos seus estudantes e quais suas principais dificuldades em abordar temas com esse viés.

\section{SUJEITOS DA PESQUISA, COLETA DE DADOS E TÉCNICA DE ANÁLISE}

Os sujeitos de pesquisa consistiram em 29 professores das redes pública e privada dos estados de Minas Gerais e Rio Grande do Sul. Os mesmos responderam a um questionário que tinha como objetivo fornecer aos pesquisadores informações que lhes permitissem elaborar um perfil do grupo de entrevistados. Todos os participantes que se engajaram na pesquisa foram convidados e sua participação foi voluntária, mediante seus respectivos consentimentos para divulgação dos resultados sob o compromisso de confidencialidade por parte dos pesquisadores.

Além de questões objetivas, este mesmo instrumento de coleta de dados ainda possuía duas perguntas abertas de caráter dissertativo, a saber: (a)como - e em que momentos - você observa que sua disciplina (em termos de conteúdos e metodologias) contribui para a construção de saberes e o fomento à cultura que permitam os estudantes experienciarem práticas cidadãs, fazendo-os reconhecer direitos e deveres que assegurem

Crquivo Brasileiro de Educação, Belo Horizonte, v. 5, n. 12, set-dez, 2017. 
sua participação ativa em uma sociedade democrática? e; (b) A partir de sua percepção, em termos curriculares, de trabalho pedagógico (na relação que pode se estabelecer entre diferentes áreas do conhecimento), de avaliação (conteúdos e metodologias) e do capital cultural como um todo disseminado pela escola, qual seria uma possível saída para que a sua disciplina - a partir da organização escolar atual - pudesse contribuir para uma participação ativa dos estudantes em uma sociedade democrática? Para responder estas questões pediu-se aos entrevistados, justificativas para seus argumentos utilizando exemplos práticos de seu cotidiano na educação básica.

As questões objetivas foram analisadas na intenção elaborar o perfil dos sujeitos participantes da pesquisa. Com relação a análise qualitativa, optou-se pelo uso da técnica de Análise de Conteúdo (BARDIN, 2011). Assim, anteriormente à leitura das questões dissertativas, elencaram-se categorias de análise a priori que constituíam o foco de interesse dos autores. São elas:

a) relação indivíduo/conhecimento, que diz respeito ao desempenho dos alunos frente as avaliações dos conteúdos do currículo-programa;

b) relação sujeito/poder-saber, que leva em consideração a capacidade de empoderamento dos alunos ao colocarem o conhecimento adquirido em diferentes disciplinas em prática, ou seja, aplicando-o e produzindo saber ao relacionarem-se com o conhecimento para resolver um problema real e;

c) relação cidadão/ambiente, que descreve elementos de uma cultura cidadã que deriva do conhecimento curricular nas diferentes disciplinas dos professores entrevistados.Além das categorias a priori, pós-análise de conteúdo, percebeu-se a necessidade da criação de outras categorias emergentes - baseadas nos conteúdos das respostas dos professores. Como categorias emergentes foram estabelecidas:

$\checkmark$ relação currículo/cidadania, que diz respeito a como os professores tem percebido - ou não - as possíveis relações entre suas disciplinas e, portanto, 
aos currículos-programa a partir dos quais desenvolvem seus planos de aula;

$\checkmark$ interdisciplinaridade, como condição de uma melhor percepção, ou desafio, para o desenvolvimento de práticas cidadãs em sua área de conhecimento;

$\checkmark$ relação professor/escola, categoria que expressa o quanto os professores podem ser incentivados por suas escolas - a partir da relação que estabelecem com as equipes que coordenam o trabalho pedagógico e até mesmo com os conteúdos programáticos que integram documentos como projeto políticopedagógico ou planos de estudos. Essa última categoria abrange também a relação que o docente estabelece em relação à liberdade de seu trabalho, seja desde a escolha dos materiais didáticos, até as metodologias que julgue adequadas para cumprir seu papel no espaço permitido pelo discurso do currículo adotado por sua instituição.

A opção pela Análise de Conteúdo deu-se pela riqueza e especificidade da técnica quando aplicada por sobre materiais de natureza linguística, icônica e semiótica (BARDIN, 2011, p.40). Segundo a autora, tal técnica se constitui como "um conjunto de instrumentos metodológicos cada vez mais sutis em constante aperfeiçoamento que se aplicam a “discursos” (conteúdos e continentes) extremamente diversificados” (BARDIN, 2011, p. 15). Após a fase de pré-análise das respostas foram elencadas unidades de registro e inseridas nas categorias tanto a priori, quanto emergentes. Na fase subsequente, a da análise propriamente dita, formularam-se hipóteses e objetivos para elaboração de indicadores para análise. Alguns destes foram aqueles que deram origem às categorias emergentes (BARDIN, 2011, p.125) cujos resultados são apresentados na seção subsequente do presente trabalho.

\section{RESULTADOS}

Os resultados obtidos a partir do questionário aplicado junto aos docentes serão apresentados de maneira dividida nas duas subseções que seguem. Na primeira delas (3.1)

@rquivo Brasileiro de Educação, Belo Horizonte, v. 5, n. 12, set-dez, 2017. 
elaborou-se um perfil dos sujeitos da pesquisa, caracterizando o grupo de professores entrevistados. Já na segunda subseção (3.2) são exploradas - em termos de conteúdo cada uma das categorias a priori e as emergentes.

\subsection{Perfil dos Entrevistados}

Os participantes da pesquisa constituíram-se de um grupo com 29 docentes, $86 \%$ residentes no Rio Grande do Sul e 14\% em Minas Gerais. 41\% com idade entre 31 e 40 anos. Sobre o tempo de atuação profissional, 45\% possui entre 6 e 15 anos, porém, 17\% encontrase no início da carreira, com cinco anos ou menos e $24 \%$ com mais de 25 anos na carreira do magistério.70\% declarou-se atuante em escolas públicas (municipais, estaduais e/ou federais), $26 \%$ em instituições de redes privadas e $4 \%$ como outros (o sujeito em questão atua em uma Organização Não Governamental), destes 54\% exercem sua docência no ensino fundamental $27 \%$ no ensino médio e $21 \%$ no momento ocupa alguma função fora da sala de aula.

Quando questionados sobre a área da formação inicial docente 69\% declararam ser das áreas constituintes das Ciências da Natureza - Biologia, Física ou Química - 17\% correspondente às Linguagens e $14 \%$ as demais áreas. $51 \%$ informou possuir um ou mais cursos de especialização, $28 \%$ possui mestrado concluído ou em andamento e $21 \%$ possui doutorado concluído ou em andamento.

\subsection{Síntese de ocorrências: análise do conteúdo das categorias a priori e emergentes}

A partir dessa seção serão relatadas as sínteses de ocorrência dos conteúdos em cada categoria estipulada. A fragmentação do texto e a posterior construção de unidades de registro foram essenciais, pois, uma vez distribuídas em diferentes categorias, produziram relevantes textos para compreensão do universo que se produziu no interior de cada uma delas

Com relação à categoria(I) relação indivíduo/conhecimento, estipulada a priori, a ideia era verificar de que modo os professores proporcionam a produção de saber, ou seja: como fazem a mediação entre o conhecimento presente nos conteúdos específicos com

@rquivo Brasileiro de Educação, Belo Horizonte, v. 5, n. 12, set-dez, 2017. 
seus estudantes. A ênfase observada nessa categoria foi massivamente relacionada à metodologia. Destaca-se fortemente uma metodologia dialética, desenvolvida a partir da promoção de debates.

Os entrevistados acreditam que a discussão incentivada em sala de aula e mediada pela figura do professor contribui para que os alunos desenvolvam uma visão mais crítica, ao mesmo tempo em que refletem sobre temáticas contextualizadas, aproximadas de seu cotidiano. Assim, a inserção dos conteúdos curriculares junto à realidade dos estudantes, faz com que todos se manifestem, complexificando a discussão. Dessa forma, mais saber se produz, novas ideias para intervenções em diferentes contextos surgem.

As dimensões da prática e da experiência foram muito exploradas pelos professores nessa categoria. Segundo os professores, a riqueza do debate permite a realização de diferentes tipos de avaliação que, verdadeiramente, promovam seus estudantes. A retirada dos alunos do contexto de sala de aula de forma regular também é valorizada. A visita a museus, saídas de campo e outros espaços permite com que os conteúdos, ao se aproximarem do real - da história -, produzam mais sentido. Entender a relação de um conteúdo teórico e aplicação prática, de acordo com os sujeitos de pesquisa, é fortalecer o elo que evidencia o sentimento de pertença dos alunos à sociedade, sendo, também, mote para discussão sobre seus direitos e deveres.

A tão abordada estratégia dialógica na categoria anterior, juntamente com a necessária contextualização e aproximação da realidade, evidenciada nos discursos dos professores entrevistados parece ter seus efeitos quando se trata de discutir a (II) relação sujeito/saber-poder. Esta outra forma de conduzir as aulas, tornando os alunos, inclusive, mais protagonistas de sua própria aprendizagem acaba por empoderá-los, pelo menos em dois sentidos evidenciados nas respostas obtidas.

O primeiro deles diz respeito ao nível e a atualização das discussões. Ao dar voz aos alunos os professores perceberam que, ao abrirem espaços para perguntas e questionamentos, invariavelmente os alunos tomavam os exemplos dados como referência para questionar acontecimentos atuais. Assim, nas aulas de ciências, por exemplo, muitas discussões acabavam sendo direcionadas ao campo histórico e sociológico, o que em uma "aula tradicional", segundo nossos entrevistados, a tendência de isso acontecer era quase mínima.

@rquivo Brasileiro de Educação, Belo Horizonte, v. 5, n. 12, set-dez, 2017. 
Ainda, percebeu-se por parte dos docentes um empoderamento em outro sentido: no da participação não apenas na aula, mas em outros setores da escola. O chamamento à crítica e à necessidade de reflexão, juntamente com o nível mais elevado de problematização, fez com que os professores notassem um maior engajamento dos alunos em eventos escolares, bem como promoveu maior conscientização sobre temas como igualdade e respeito à reinvindicação de direitos de grupos distintos. Os entrevistados percebem que a partir disso, o diálogo também aumenta entre seus alunos, desde quando são desafiados a resolver um problema proposto em sala de aula, por meio de uma metodologia ativa, até em termos de prontidão de escuta de problemas relacionados à turma.

Evidenciou-se, a partir da fala dos professores, que o que acaba mais sendo colocado em prática é uma postura de escuta, de respeito a opinião do diferente. Em relação a conteúdos, destacou-se que aqueles ligados a questões econômicas, de gênero e tecnológicos são os mais utilizados pelos alunos para (auto)afirmar seus conhecimentos, fazendo-os adotarem posturas de escolha, mais conscientes dos efeitos que derivam de suas tomadas de decisão. Assim a dimensão dessa aprendizagem se encontra mais aprofundada e, portanto, mais sedimentada a partir daquilo que pode ser observado na categoria anterior que diz respeito a aproximação dos estudantes com o mundo real.

A categoria (III) relação cidadão/ambiente é retratada pela capacidade de possíveis intervenções que os estudantes podem começar a realizar em um contexto social se, de acordo com os professores, "se propuserem a estudar e dominar os conteúdos". Percebe-se que cada um dos entrevistados, ao falar de sua disciplina, valeu-se de uma certa intenção de valorizá-la frente ao que o conhecimento de cada uma delas pode proporcionar para garantir uma "vida melhor em sociedade".

As ocorrências mais evidentes aqui foram das disciplinas do campo científico. " $A$ disciplina de ciências contribui muito para os alunos serem ativos numa sociedade democrática" (sujeito 16). Percebeu-se que as falas, implicitamente, atrelam a importância das ciências ao desenvolvimento de tecnologias. Assim, dominar o uso das tecnologias não seria suficiente, sendo necessário um entendimento por parte do aluno sobre como determinados aparatos tecnológicos funcionam. Nesse sentido, percebeu-se que os professores dessas áreas têm incentivado não apenas a alfabetização científica, mas

@rquivo Brasileiro de Educação, Belo Horizonte, v. 5, n. 12, set-dez, 2017. 
ao que se convencionou se chamar de letramento científico: o uso/aplicação social de conteúdos associada a uma leitura de mundo por meio de "lentes da ciência". Todavia ressalta-se a importância de um diálogo horizontal, preconizando a igualdade entre as áreas do conhecimento, pois para a formação de cidadãos não são apenas conteúdos curriculares que estão em jogo, mas sujeitos atuando na formação de outros sujeitos.

A categoria (IV) relação currículo/cidadania constitui uma das três estipuladas $a$ posteriori, sendo, portanto, emergente. Nela constatou-se o quanto alguns professores percebem a relação dos conteúdos nucleares de suas disciplinas com relação às práticas cidadãs. A maior evidencia dessa percepção se encontra nas falas dos docentes que afirmam que os conteúdos trabalhados em aula, "dependendo da forma como são discutidos", possibilitam o "desenvolvimento de um raciocínio sobre direitos e deveres" por parte dos estudantes. Os professores expõem alguns temas como sexualidade e meio ambiente como assuntos que naturalmente conduzem a discussões que envolvem um posicionamento enquanto cidadão, encaminhando-se para debates como: planejamento familiar, paternidade/maternidade responsável, consumismo, sustentabilidade, descarte de resíduos, etc.

Percebe-se, ainda, que na concepção dos professores essa relação só pode acontecer em uma ordem política, onde "se todos cumprissem seus deveres e soubessem reivindicar seus direitos" chegaríamos a um estado de "sociedade ideal". Junto à esfera política, à esfera cultural apareceu no sentido de "acesso à cultura" de aceitação às diferentes culturas. O fato a ser destacado, aqui, é que a dimensão cultural foi associada ao conhecimento, sua acumulação e não a uma série de significados compartilhados por diferentes culturas fazendo com que algumas se aproximem mais de outras. Percebe-se que a questão cultural aparece como essencial no exercício da cidadania. Com isso, frequentar a escola, aprender, para esse grupo de professores é tomado como sinônimo de aceitação social.

Embora nenhum professor tenha evidenciado de maneira direta a relação currículo cidadania, a percepção que só por meio da aprendizagem surge a "aceitação social" e uma melhor inserção nesse contexto, nos faz subentender a importância do viés que acabam por conferir à educação e ao trabalho pedagógico.

Em termos de $(\mathrm{V})$ interdisciplinaridade o que se sobressalta, em primeiro lugar, é a

@rquivo Brasileiro de Educação, Belo Horizonte, v. 5, n. 12, set-dez, 2017. 
importância que os professores conferem ao trabalho interdisciplinar. Além disso, entendem que ao fomentar a discussão e, ao abrir espaço para a pergunta do aluno, é praticamente impossível que os próprios questionamentos não apresentem um caráter interdisciplinar. Assim, ao investirem em metodologias ativas para a condução de suas aulas, os professores constatam um maior interesse por parte dos estudantes a partir do que consideram como sendo uma "participação efetiva”, fruto do protagonismo já citado na análise de categorias anteriores.

Outra questão interessante a ser considerada é a consequência de uma abordagem interdisciplinar. Segundo relatos dos docentes, essa realidade acaba fazendo com que os estudantes necessitem extrapolar os muros da escola para acharem as respostas para perguntas cada vez mais complexas. Visitas a museus, centros de ciências e o diálogo com Organização Não Governamental(ONGs) foram atividades citadas no que tange à satisfação das exigências naturais de uma abordagem interdisciplinar.

Dentre os obstáculos que alguns professores relatam ao trabalho interdisciplinar com foco à cidadania, a palavra “engessado" associado ao currículo é frequentemente encontrada, colocando-se como dificuldade o excesso de conteúdos a serem trabalhados e as imposições de uso de materiais didáticos. Diante dessas questões, as necessidades dos estudantes em discutir determinado tema são mais urgentes que o cumprimento de um conteúdo estagnado em planejamentos escolares. Essas situações são recorrentes em salas de aula e não devem ser ignoradas. O trabalho visando a construção cidadã é o fio condutor dos temas transversais, os quais devem permear todas as disciplinas, nos diferentes níveis de ensino. Portanto, é dever do professor, independente de disciplina a qual lecione auxiliar nessa formação.

Frente a essa realidade, destacou-se, também, a opção pela pedagogia de projetos. Os projetos de trabalho foram apresentados como metodologia ativa satisfatória para atender diferentes demandas dos estudantes em relação aos temas trabalhados e tiveram sua potencialidade destacada para uma aprendizagem conduzida também pelos discentes. Um dos professores, ainda, citou a transdisciplinaridade, mas sem fundamentar, não relatou um exemplo concreto de prática transdisciplinar, talvez, aqui, entendida apenas como maneira de perceber o mundo e as relações na escola. Outro professor explicita ao pensar em caminhos que auxiliem na formação cidadã:

@rquivo Brasileiro de Educação, Belo Horizonte, v. 5, n. 12, set-dez, 2017. 
Já trabalho dentro de uma perspectiva que reúne algumas áreas de conhecimento que vão além da arte em si, entretanto gostaria de sensibilizar demais colegas meus para que construíssemos um trabalho pedagógico mais amplo e inter e transdisciplinar. Talvez, esta seja não a saída, mas o clímax para atingir ainda mais os objetivos educativos traçados isoladamente por cada professor. (Sujeito 20)

A prática transdisciplinar citada por este professor parece estar atrelada a parcerias entre docentes. 0 trabalho transdisciplinar não depende apenas das pontes estabelecidas entre as disciplinas por meio dos docentes, mas muito mais da disposição de cada sujeito em avançar entre as áreas, sem levantar barreiras. A pedagogia de projetos citada pelos próprios depoentes favorece ações conjuntas, mas o que não impede a construção individual do professor com sua turma de uma forma própria de se relacionar e produzir saberes além da disciplina.

Ainda, como categoria, a (VI) relação professor/escola, foi percebida na fala dos docentes em termos de apoio que as instituições de ensino oferecem para que os mesmos coloquem em ação práticas pedagógicas que lhes confiram certa liberdade metodológica. Nesse sentido, muitos professores relataram a importância da parceria das equipes pedagógicas para uma educação que fuja daquilo que os mesmos consideram como sendo "tradicional".

Aqui, cabe ressaltar, que a "liberdade" relatada pelos docentes se estende também para o diálogo estabelecido com a escola em momentos em que se deve decidir elementos relacionados ao planejamento e ao calendário de atividades. A isso, em termos de planejamento, considera-se, por exemplo, o apoio da escola ao oferecer "suporte a práticas de pesquisa", que estimulem a curiosidade dos alunos. Assim a "maleabilidade" que algumas escolas proporcionam é considerada como essencial para a execução de um "trabalho diferenciado" com os alunos, permitindo - também -, o maior relacionamento com as famílias.

A crítica, por parte dos professores, vem exatamente no sentido contrário. Em determinados pontos as escolas são, um tanto, intransigentes/autocráticas em relação a algumas decisões. Um exemplo já comentado, mas que nos remete também a esta situação é o “engessamento em relação à escolha dos materiais didáticos”. Isso também se estende, à questão do uso dessas matérias, pois quando o professor não tem oportunidade de 
escolhê-los e faz uso de algum material complementar em substituição ao “oficial”, muitas vezes é alvo de algum tipo de advertência.

Um ponto positivo a ser destacado, ainda nessa categoria, caracterizou apenas uma ocorrência, mas importante na fala dos docentes: o apoio da escola para um maior número de ações junto à comunidade na qual a mesma se encontra inserida. Exatamente o que vai ao encontro do que se propõe a analisar este trabalho. $O$ docente que faz esta observação em seu relato, implicitamente, relaciona o conhecimento da realidade da comunidade como possibilidade para o exercício de ações que "transformem" não apenas os estudantes que as executam, mas também o espaço sobre o qual ocorrem tais intervenções.

\section{CONSIDERAÇÕES FINAIS}

Ao longo dos escritos dos professores, percebem-se em seus exemplos de práticas realizadas ao longo dos anos de trabalho, as suas "maneiras" de contribuir para um ensino dentro do que os Parâmetros Curriculares Nacionais preconizam como a compreensão de cidadania. Contata-se em vários dos depoimentos a importância atribuída a "sua" disciplina e o quanto essa pode favorecer a construção cidadã do sujeito em formação.

Nessa perspectiva, um trabalho colaborativo, que propicie aproximações entre os atores (entre docentes; entre setores; entre escola e comunidade), trazendo clareza às questões, discutindo propostas, democratizando o espaço escolar se mostra necessário, estabelecendo direitos e deveres, efetivando a construção cidadã na prática cotidiana.

Isso se apresenta como possibilidades de propostas que fomentem a construção de uma cidadania relacionada às diferentes realidades a realização de projetos que aproximem à escola da comunidade. Estas ideias vêm ao encontro da popularização das feiras científicas, que nos últimos anos, vem adotando um caráter social aos temas propostos aos projetos inscritos, exigindo uma participação na comunidade a qual a escola se insere e com isso um olhar aos problemas da "vida real" em busca por soluções e/ou alternativas. 
45

REFERÊNCIAS

BARDIN, L. Análise de conteúdo. São Paulo: Edições 70, 2011.

BRASIL. Secretaria de Educação Fundamental. Parâmetros Curriculares Nacionais: terceiro e quarto ciclos: apresentação dos temas transversais. Brasília: MEC/SEF, 1998.

BRASIL. Ministério da Educação. Secretária de Educação Básica. Diretoria de Currículos e Educação Integral. Diretrizes Curriculares Nacionais da Educação Básica. Brasília: MEC, SEB, DICEI, 2013.

MOREIRA, A. F.; CANDAU, V. M. Indagações sobre o currículo: currículo, conhecimento e cultura. Brasília: Ministério da Educação, Secretaria da Educação Básica, 2007.

MOREIRA, A. F.; TADEU, T. Sociologia e teoria crítica do currículo: uma introdução. In: MOREIRA, A. F.; TADEU, T. (Org.) Currículo, cultura e sociedade. 12. ed. São Paulo: Cortez, 2011. p. 13-48.

@rquivo Brasileiro de Educação, Belo Horizonte, v. 5, n. 12, set-dez, 2017. 